\title{
A regulamentação dos preços dos planos individuais de saúde
}

\author{
CARLOS OCTÁVIO OCKÉ-REIS* \\ SIMONE DE SOUZA CARDOSO
}

Pricing regulation of Brazilian private health insurance. Aggregate price indices measure variations in nominal prices. In this paper, we compare the inflation rates of the general economy and those of the health sector and private health insurance market between 2001 and 2005, based on the indices of Departamento Intersindical de Estatística e Estudos Socioeconômicos, of Fundação Instituto de Pesquisas Econômicas, of Instituto Brasileiro de Geografia e Estatística and IPEADATA database, to the private health insurance readjustment applied by the National Private Health Insurance Agency (ANS). The health sector inflation rate was found stable and inferior to the general one, what would validate applying lower readjustments derived from official price indices.

Keywords: Bundle pricing, health care markets, regulation, government policy JEL Classification: D40, I11, I18

\section{INTRODUÇÃO}

O desenvolvimento de estudos econômicos na área da atenção médica permite ao Estado, por meio da aplicação de políticas públicas, administrar problemas relacionados às políticas, instituições e serviços de saúde, no tocante ao financiamento, à gestão e à regulação. Se a adoção dos critérios de eficiência e equidade é aceita comumente pela comunidade científica, ${ }^{1}$ as 'falhas de mercado', que justificam a intervenção governamental no mercado de serviços de saúde, não prescrevem

\footnotetext{
${ }^{1}$ Piola e Vianna (1995).

* Instituto de Pesquisa Econômica Aplicada. E-mail: carlos.octavio@ipea.gov.br. Agência Nacional de Saúde Suplementar. carlos.octavio@ans.gov.br. Instituto de Pesquisa Econômica Aplicada. E-mail: simone.cardoso@ipea.gov.br. Submetido: Março 2009: aprovado Dezembro 2009.
} 
um comportamento único intrínseco à atividade regulatória (natureza, objetivos, desenho institucional etc.). Nessa linha, este artigo pretende contribuir para iluminar e analisar certos aspectos da regulamentação dos preços dos planos individuais de saúde no Brasil.

Ao estudar o mercado norte-americano - similiar ao caso brasileiro ${ }^{2}-$ Cutler e Zeckhauser (2000) afirmam que o mercado de serviços médicos apresenta características distintas das demais atividades econômicas porque: (i) a demanda é potencialmente inelástica (necessidade social); (ii) a oferta cria a própria procura (supplier-induced demand); (iii) as informações são assimétricas (conflito 'agente'/'principal'); (iv) as externalidades produzidas pelos bens públicos não favorecem o predomínio da lógica de mercado na alocação dos recursos.

A dinâmica do mercado de planos de saúde brasileiro é influenciada ademais por uma série de motivos, ${ }^{3}$, tais como: taxa de juros (custos de oportunidade); taxa de câmbio (dependência da importação de insumos e de equipamentos médicos); estrutura de concentração e diferenciação dos produtos (barreiras à entrada e seleção de pacientes de baixo risco [cream skimming]); incorporação de tecnologia (motivada pela dinâmica do complexo médico-industrial); probabilidade do risco de adoecer, taxa de utilização dos serviços e juros futuros (lógica atuarial); rigidez dos fatores de produção (baixa mobilidade-substituição e alto grau de especialização) e baixa produtividade do trabalho.

Vale dizer, as possibilidades de avanço da produtividade no setor são restritas em relação às demais atividades econômicas. Ao se observar o tratamento individual como o produto dos serviços, a expansão do conhecimento médico e tecnológico poderia significar a dedicação de mais tempo de trabalho por 'unidade de produção'. Baumol denomina esse fenômeno como 'doença dos custos'.(Baumol, 1993) Dada a existência de diferenciais de produtividade entre os setores de bens e de serviços, o trabalho se relaciona de forma diferente com a produção; no caso de setor de bens, o trabalho estaria incorporado ao produto; já no setor de serviços, o trabalho seria o produto que estaria sendo trocado, dificultando a substituição de fatores.

O caráter non-tradable e os custos de transação associados aos prazos de carência e à procura de uma rede credenciada de qualidade vêm confirmar um traço suis generis nesse mercado, que acaba pressionando o nível de preços e a taxa de inflação dos planos de saúde: os custos crescentes à moda de Baumol, que tornam, em geral, a inflação setorial e a dos planos de saúde maior do que a taxa de inflação da economia. (Médici, 1992)

Nesse ambiente econômico, é plausível pensar que o funcionamento do mercado de planos de saúde não consiga garantir livremente preços acessíveis, cobertura integral e qualidade de atenção médica. Do ponto de vista de seu padrão de competição, estaria configurado um quadro de concorrência imperfeita, onde os

\footnotetext{
${ }^{2}$ Perillo.(2008).

${ }^{3}$ Ocké-Reis, Silveira e Andreazzi (2006) e Ocké-Reis (2002).
} 
preços tenderiam a aparecer como 'preços de monopólio' (Phelps, 1997), pois vendedores poderiam fixar maiores lucros em detrimento do bem-estar social dos consumidores.

Desse modo, justifica-se a regulamentação dos preços de planos individuais de saúde, atividade, hoje, de competência legal da Agência Nacional de Saúde Suplementar (ANS), de acordo com a Lei 9.961, promulgada em 2000, em seu capítulo I, art. $4^{\circ}$, inciso XVII, cabendo à agência reguladora “(...) autorizar reajustes e revisões das contraprestações pecuniárias dos planos privados de assistência à saúde, ouvido o Ministério da Fazenda (redação final da Medida Provisória n 2.177 44, de 24 de agosto de 2001)". ${ }^{4}$

Considerando-se o tamanho do mercado de planos de saúde, cuja cobertura abrange boa parte do mercado formal de trabalho e o de funcionários públicos, o raio de ação de tal reajuste é pequenino, pois não abarca os planos coletivos, que são a maioria, sejam eles empresariais ou por adesão. Desse modo, as operadoras são obrigadas, apenas, a informar à agência os índices de reajuste dos planos coletivos.

Neste artigo, comparamos a taxa de inflação da economia, a do setor saúde e a dos planos de saúde com os reajustes dos planos individuais aplicados pela ANS no período de 2001 a 2005.

Ao longo da próxima seção, apontamos breves características dos índices. A seguir, na terceira seção, analisa-se o comportamento da taxa de inflação da economia, a do setor saúde e a dos planos de saúde, comparando-o com os reajustes dos planos individuais. Por sua vez, na quarta seção, discutimos a consistência dos resultados encontrados na terceira seção. Resulta desse trabalho, entre outros, a percepção de que a estável taxa de inflação do setor saúde foi inferior à inflação da economia, o que legitimaria a aplicação de reajustes menores com base nos índices oficiais de preço. Assim, nas considerações finais, formulamos duas propostas de política, que poderão ser examinadas em estudos posteriores.

\section{BREVES CARACTERÍSTICAS DOS ÍNDICES DE PREÇO}

O cálculo dos índices de preços ao consumidor costuma gerar controvérsias dada a complexidade para se definir o nível e a variação dos gastos dos indivíduos. Não é fácil mensurar o peso dos diversos bens e serviços que compõem a cesta de consumo das famílias, cuja estrutura de ponderação retrata a participação dos produtos no orçamento doméstico. (Singer, 1980)

É igualmente comum observar que a metodologia de cálculo dos índices da saúde é cercada de controvérsias. Quando mal aplicada, torna difusa a identificação das principais causas de elevação dos gastos das famílias com saúde — que constitui um bem vital à sociedade. Este não é certamente um problema desprezível,

${ }^{4}$ Agência Nacional de Saúde Suplementar (2000). 
posto que as características econômicas e institucionais do mercado de seviços de saúde dificultam a apuração dos preços relativos de insumos e bens finais e da própria agregação do produto, além de tornar delicada a possibilidade de mensurar a produtividade das atividades médico-hospitalares. ${ }^{5}$

Nessa mesma linha, a literatura econômica alerta para os cuidados que devemos ter ao analisar os impactos da inflação do setor saúde sobre a economia, o sistema de saúde e a população: seja para indicar com precisão a participação do setor saúde no Produto Interno Bruto (PIB) ou para avaliar a eficiência e a eqüidade das políticas e programas de saúde. ${ }^{6}$

O fenômeno da inflação dos planos de saúde se caracteriza pelo aumento continuado dos preços, do que resultaria perda do poder aquisitivo das famílias. Da óptica da 'cesta' do consumidor, que agrega bens e preços diversos, imaginemos que os prêmios tenham crescido $15 \%$. Seria importante saber que parcela desse incremento se deu em função do aumento da quantidade consumida de serviços médico-hospitalares e qual a que se deveu ao aumento de preços (considerando o aumento dos custos, a introdução de novas tecnologias etc.). A dificuldade de se responder a essa questão provém do fato de que as diferentes quantidades consumidas e os diferentes preços conformam grandezas heterogêneas.

As taxas de inflação da economia, do setor saúde e dos planos de saúde foram investigadas a partir dos índices de preço do Departamento Intersindical de Estatística e Estudos Socioeconômicos (Dieese), os da Fundação Instituto de Pesquisas Econômicas (Fipe), os do Instituto Brasileiro de Geografia e Estatística (IBGE) bem como da base de dados macroeconômicos, financeiros e regionais do Ipeadata. Esses índices foram comparados com o reajuste dos planos individuais entre maio de 2001 e abril de 2005 (o mês de maio corresponde à data-base de aplicação anual do reajuste). Vale dizer, esses índices são oficiais e gozam de reputação científica, além de serem plenamente aceitos pelas autoridades governamentais, pela sociedade civil organizada e pela imprensa.

Cabe destacar ainda que a agência reguladora autoriza e aplica diferentes tipos de reajuste de preço, relacionados à mudança de faixa etária, à revisão técnica, à adaptação de planos antigos, à assinatura de termos de compromisso ou, ainda, à presença de franquias e a co-pagamentos, que acabam afetando o nível e a inflação do setor. Para efeito deste artigo, examinamos apenas o reajuste dos planos individuais da ANS com os índices de preço mencionados acima, que captam de forma imprecisa esses diversos tipos de reajuste.

\footnotetext{
${ }^{5}$ Newhouse (2001) e Berndt et al. (2005).

${ }^{6}$ Newhouse (2002).
} 


\section{Dieese}

O Dieese coleta diretamente os preços dos planos de assistência à saúde junto às operadoras. Grosso modo, caso haja mudança ou inovação no plano selecionado, mantém-se a seqüência única para acompanhar a evolução dos preços do plano substituto.

O Índice de Custo de Vida (ICV) apura a variação mensal dos preços dos bens e serviços consumidos no município de São Paulo pelas famílias com renda média de até $\mathrm{R} \$ 2.800^{7}$. É digno de nota que, em 2005, esse munícipo detinha um mercado - relevante - de 6,3 milhões de planos. ${ }^{8}$

Para obter o ICV, aplica-se a fórmula de Laspeyres, pela qual a elasticidade-preço da demanda é igual a 0 (zero); de acordo com essa metodologia, apesar da variação do preço de um componente, o consumo físico será igual. Desse modo, o peso de cada componente varia direta e proporcionalmente ao aumento de preço: quanto maior for o aumento no preço de um componente, maior será sua participação no índice (Kirsten, 1985). Por conseguinte, essa fórmula não capta o efeito-substituição no consumo, podendo criar artificialmente uma taxa de inflação superestimada. ${ }^{9}$

No índice de preço da saúde, a cesta de consumo do Dieese está dividida em três itens: (1) assistência médica; (2) aparelhos e próteses; (3) medicamentos e produtos farmacêuticos. Há informação desagregada sobre a inflação dos planos de saúde no item 'assistência médica', sendo o único índice a apresentar dados relativos aos planos empresariais.

Em sua última Pesquisa de Orçamento Familiar (POF), de 1994-95, o peso original do plano individual na composição do grupo saúde foi maior do que aquele atribuído ao plano empresarial; na verdade, aplicou-se um redutor correspondente à transferência monetária sob a forma de salário indireto, pago pelos empregadores aos empregados, para o financiamento misto ou integral dos planos de saúde dos trabalhadores e executivos.

\section{Fipe}

O IPC-Fipe apura a variação mensal de preços dos bens e serviços consumidos pelas famílias com renda média entre 1 e 20 salários mínimos, no município de São Paulo. Aplica-se a fórmula de Könus-Byushgens (índice geométrico), em que a elasticidade-preço da demanda é igual a 1 para cada subitem, cujos pesos são obtidos diretamente da sua POF (Carmo, 2004).

\footnotetext{
${ }^{7}$ Dieese (1997).

8 Agência Nacional de Saúde Suplementar (2006), Ocké-Reis e Cardoso (2006).

${ }^{9}$ Banco Central do Brasil (2004).
} 
Esse método permite a substituição do consumo dos bens e serviços que tiveram aumento relativo por aqueles que ficaram relativamente mais baratos, podendo captar assim o efeito-renda e o efeito-substituição, e é apurado com base no conceito de caixa, ou seja, somente contabiliza o reajuste quando os gastos das famílias são afetados. Baseia-se na POF do município de São Paulo realizada pela Fipe entre 1998 e 1999 e adotada em janeiro de 2000.

O período de coleta vai do primeiro ao último dia de cada mês e o dia de divulgação do IPC-Fipe é no terceiro dia útil após o término da coleta. Semanalmente ocorrem divulgações prévias, chamadas quadrissemanais, que comparam os preços das últimas quatro semanas apuradas com as quatro semanas imediatamente anteriores, auferindo um índice mensalisado para cada semana do mês. (Rizzieri e Carmo, 1995)

No índice de preços da saúde, a cesta de consumo da Fipe está dividida em quatro itens: (1) aparelhos corretivos; (2) contrato de assistência à saúde (i.e. planos de saúde); (3) serviços médicos e laboratoriais; e (4) remédios e produtos farmacêuticos.

Quanto ao painel de domicílios acompanhados pela Fipe, a amostra é, em um primeiro exame, representativa quanto aos gastos das famílias com planos individuais e empresariais, novos e antigos, mas o IPC não capta os aumentos dos planos, caso haja mudança das faixas etárias (capta somente o aumento de preços ocorrido no produto original demandado pelo consumidor).

\section{IBGE}

O Índice de Preço ao Consumidor Amplo (IPCA) apura a variação mensal de preços dos bens e serviços consumidos pelas famílias com renda média entre 1 e 40 salários mínimos em nove regiões metropolitanas, no Distrito Federal e na capital de Goiás. É um índice oficial que mede a cesta de consumo de famílias. Os índices nacionais são calculados a partir dos resultados dos índices regionais (média aritmética ponderada). Aplica-se também a fórmula de Laspeyres. A partir dos resultados do IPCA do mês de junho de 2006, o IBGE passou a calcular os índices com base nas estruturas de gastos de consumo da POF que foi utilizada no período de julho de 2002 a agosto de 2003 (em lugar da POF 95-96).

No índice de preço da saúde, a cesta de consumo do IBGE está dividida em três itens: (1) cuidados pessoais; (2) produtos farmacêuticos e ópticos; e (3) serviços de saúde - aspecto que inclui o item plano de saúde. Para monitorar a variação de preços dos planos individual e/ou familiar são registrados os percentuais de reajuste incidentes sobre os contratos assinados com período de um ano ou mais desde 2001. A cada mês e em cada região do país, as operadoras com maior número de usuários são visitadas, obtendo-se a informação do percentual de reajuste aplicado sobre a mensalidade dos contratos que aniversariam no mês da pesquisa. O percentual informado segue, em geral, o fixado pela ANS, com vistas a vigorar nos doze 
meses seguintes à sua aplicação. Considerando, por hipótese, que 1/12 de usuários da carteira de uma operadora tenha seu contrato com aniversário em cada um dos meses do ano, ao final de doze meses, no acumulado, os índices de preços do IBGE terão refletido o total dos reajustes de fato ocorridos sobre os contratos. ${ }^{10}$

Em 2004, o IBGE passou a ponderar o cálculo da variação das mensalidades em relação à data da Lei da regulamentação, pois, a partir daí, se demarcam distintos regimes regulatórios: ${ }^{11}$ os contratos assinados pelos consumidores antes da Lei 9.656 foram ponderados em 58\% (31/12/1998); já aqueles assinados depois da Lei foram ponderados em $42 \%$. Em 2005, ademais, os reajustes dos contratos antigos com índice próprio não foram levados em conta pelo IBGE, permanecendo a coleta limitada aos planos individuais.

\section{REAJUSTES DA ANS EM FACE DA INFLAÇÃO DO SETOR SAÚDE}

Segundo a agência reguladora, as operadoras devem obter sua autorização para a comercialização dos planos individuais novos que cobrem os serviços de assistência à saúde com ou sem odontologia, antes de aplicar os reajustes às mensalidades.

Os reajustes estão circunscritos aos planos de assistência à saúde individual e familiar com contratos realizados a partir de 1999, assim como aos planos de autogestão não-patrocinados e aos planos anteriores à Lei $9.656 / 98$ não-adaptados, cujas cláusulas contratuais não indiquem claramente o índice ou os critérios para fins de cálculo de reajuste.

A rigor, tais reajustes não representam tabelamento do valor nominal dos planos individuais, mas apenas um percentual de reajuste para os contratos novos com mais de um ano; em outras palavras, conformam um teto fixado anualmente, que delimita a variação dos prêmios e as contraprestações pecuniárias. Dessa maneira, a partir de 2000 passa a existir uma demarcação do teto de reajuste dos preços dos planos individuais novos e não um controle de preços stricto sensu. Em síntese, o preço mínimo de entrada só tem o seu piso regulado, mas não seu teto, para evitar, sobretudo, as práticas de dumping (preço abaixo do custo para afastar concorrentes).

Desde 2001, a ANS estabelece um índice de reajuste dos planos individuais a partir da média dos aumentos dos planos coletivos dos últimos doze meses (exceto os planos com até 50 beneficiários ou os que não têm patrocinador). Essa metodologia, inspirada no modelo de regulação por desempenho (yardstick competition $)^{12}$,

\footnotetext{
${ }^{10}$ IBGE (2004).

11 Ocké-Reis e Cardoso (2006).

12 Possas, Pondé e Fagundes (1997).
} 
procura reduzir custos e eliminar os excessos de assimetria de informação (p.ex. são diversas operadoras e planos regulados), ao definir o teto de reajuste com base em um mercado específico de referência.

Em 2005, o reajuste atingiu 5,4 milhões de planos, ou seja, tão-somente 14,9\% de um conjunto de 36 milhões de planos de assistência à saúde (excluindo os planos dos institutos de previdência estadual e municipal e as forças armadas) $)^{13}$, subtraindo-se daí os planos odontológicos e os das instituições do setor público. Esse percentual se refere ao número de planos (i.e., vínculos de 'beneficiários' incluindo os dependentes) e não ao número de usuários, de acordo com o sistema de informação da ANS. ${ }^{14}$

Na Tabela 1 compara-se o reajuste da ANS com a taxa de inflação da economia, a do setor saúde e a dos planos de saúde entre maio de 2001 e abril de 2005. Sem maiores sofisticações estatísticas, pode-se dizer que são apresentados dados marcantes:

TABELA 1: Taxa de Inflação acumulada: maio de 2001 - abril de 2005 (\%)

\begin{tabular}{|c|c|c|c|c|c|c|c|c|c|c|}
\hline \multirow{3}{*}{ Período } & \multicolumn{10}{|c|}{ Taxas } \\
\hline & \multirow{2}{*}{$\begin{array}{c}\text { Reajuste } \\
\text { ANS }\end{array}$} & \multicolumn{3}{|c|}{ Geral } & \multicolumn{3}{|c|}{ Saúde } & \multicolumn{3}{|c|}{ Planos de Saúde } \\
\hline & & Dieese & Fipe & IBGE & Dieese & Fipe & IBGE & Dieese & Fipe & IBGE \\
\hline Maio de & & & & & & & & & & \\
\hline $\begin{array}{c}\text { 2001-Abril } \\
\text { de } 2005\end{array}$ & 42,95 & 46,69 & 36,99 & 43,44 & 83,65 & 36,12 & 36,26 & 128,59 & 41,34 & 40,83 \\
\hline
\end{tabular}

Fontes: ANS, ICV/Dieese, IPC/Fipe, IPCA/IBGE e IPEADATA. Elaboração própria.

i) o reajuste de $42,95 \%$ da ANS seguiu de perto a taxa de inflação da economia de 43,44\% medida pelo IBGE. Esse é o índice oficial utilizado pelo Banco Central do Brasil (Bacen) para o acompanhamento do regime de metas da inflação;

ii) o reajuste de $42,95 \%$ da ANS ficou acima das taxas de inflação do setor saúde medidas pela Fipe e IBGE, que são respectivamente 36,12\% e 36,29\%. Em tese, esta discrepância teria sido mais dilatada se, de um lado, os planos de saúde fossem expurgados do cálculo da taxa de inflação setorial e, de outro, se a redução dos preços de bens e serviços, negociada pelas operadoras líderes, fosse captada pelos índices de preço ao consumidor, considerado seu maior poder de barganha, o menor risco de inadimplência e as economias de escala;

iii) a taxa de inflação do Dieese revelou que os preços dos planos cresceram $128,59 \%$, bem acima do reajuste autorizado pela ANS. Ao contrário de outros índices, o Dieese coleta diretamente os preços dos planos empresariais e capta os

\footnotetext{
13 Bahia e Luiz (2006).

14 ANS (2006).
} 
contratos dos planos individuais com menos de um ano, em especial o aumento dos preços das faixas etárias mais elevadas.

No Gráfico 1, evidencia-se que a a inflação do setor saúde foi estável no período. Em especial, constata-se que, em todos os anos, o teto de reajuste definido pela ANS entre maio de 2003 e abril de 2007 foi maior do que a taxa de inflação setorial do IPCA; essa diferença foi acentuada entre Mai05/Abr06.

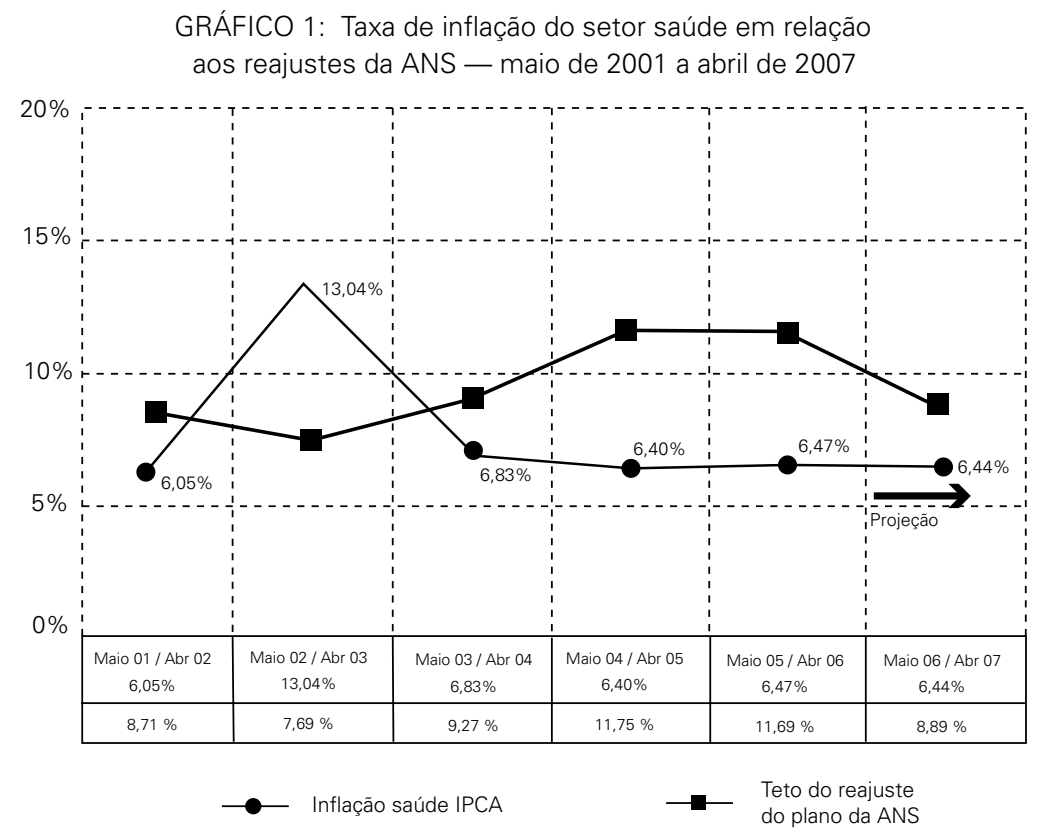

Fontes: Ipeadata, ANS e IPCA/IBGE. Elaboração própria.

Paralelamente, em agosto de 2003, o Supremo Tribunal Federal (STF) considerou inconstitucional o dispositivo que obrigava as operadoras a solicitar à ANS autorização prévia para fins de reajuste dos preços dos planos individuais antigos, naqueles casos onde os índices de reajuste não estavam previstos ou não eram claros nos contratos.

A partir de 2004, então, para resolver esse problema específico, foi celebrado um acordo formal entre a ANS e as operadoras para aplicação de um reajuste com base na variação do custo médico-hospitalar (VCMH). Esse índice espelhava, na verdade, a variação dos gastos das operadoras (e não a dos custos dos prestadores) com consultas, exames, procedimentos diagnósticos-terapêuticos e internações exceto os dispêndios comerciais e administrativos (Ocké-Reis, 2005). Com o objetivo de recuperar perdas passadas, foi também criado um resíduo, parcelado nos anos posteriores a 2004 . 
TABELA 2: ANS: Reajuste dos planos individuais de saúde antigos — julho de 2004 - junho de 2007

\begin{tabular}{lcccc}
\hline \multirow{2}{*}{ Operadoras } & Jul04/Jun05 & Jul06/Jun07 & Jul06/Jun07 & Acumulado \\
\cline { 2 - 5 } & $(\%)$ & $(\%)$ & $(\%)$ & $(\%)$ \\
\hline Sul América & 11,75 & 26,10 & 11,57 & 57,22 \\
Bradesco Saúde & 11,75 & 25,80 & 11,57 & 56,85 \\
Itaúseg & 11,75 & 25,80 & 11,57 & 56,85 \\
Amil & 11,75 & 20,07 & 11,46 & 49,56 \\
Golden Cross & 11,75 & 19,23 & 11,46 & 48,51 \\
\hline
\end{tabular}

Fontes: referências bibliográficas. Elaboração própria.

À primeira vista, havia déficit de $24,15 \%$, decorrente do hiato deixado pela política de reajuste anterior. No entanto, a Tabela 2 demonstra que o reajuste que foi aplicado nos planos individuais antigos, com base em índices próprios, foi superior ao alegado déficit de 24,15\%. Sul América, Bradesco Saúde e Itaúseg foram reajustadas em $57,22 \%, 56,85 \%$ e $56,85 \%$, respectivamente, ao passo que as empresas de medicina de grupo Amil e Golden Cross, em 49,56\% e 48,51\%.

Fica evidente que a ANS não teve força para impedir que a ineficiência contratual das grandes operadoras fosse repassada aos consumidores, seja em relação ao aumento dos prêmios, seja no tocante à perda de qualidade da atenção médica. Favorecidas pela decisão do STF de não reconhecer a agência reguladora como instância responsável pela regulação dos contratos estabelecidos antes de 1999, tais operadoras líderes (Sul América, Bradesco Saúde, Itaúseg, Amil e Golden Cross), com seu poder de mercado e beneficiadas por suas marcas e/ou pelo tamanho da sua carteira de usuários, criaram um cerco à política regulatória da agência reguladora, pressionando o reajuste de preços dos planos individuais antigos (Ocké-Reis, 2007).

Cabe então argüir: a partir do acompanhamento da inflação do setor saúde, seria aceitável criticar esta política de reajuste?

A taxa de inflação do setor saúde foi estável e inferior à inflação da economia - resultado que legitimaria a aplicação de reajuste menor dos planos individuais, situado abaixo do patamar de $42,95 \%$, com base nos índices oficiais de preço. Além do mais, o preço de entrada (dos planos individuais novos) e o preço dos planos individuais antigos e o dos planos coletivos são regulamentados em sentido fraco, i.e., embora monitorados pela ANS, a rigor, são definidos pelo jogo do mercado - como manifesta a alta taxa de inflação dos planos de saúde do Dieese. Noutras palavras, os planos coletivos, que representavam no mínimo $65 \%$ do mercado, não têm seus preços regulamentados pela ANS, abdicando-se de todo um esforço governamental para ajustar o funcionamento do mercado.

Mas esta linha de argumentação é convincente? O tema é controvertido e não 
há forma inequívoca de avaliar as decisões de uma agência reguladora, cuja regulamentação define que os reajustes dos planos individuais se darão a partir da média dos aumentos dos planos coletivos. Nesse sentido, na próxima seção, examinaremos mais a fundo a consistência do nosso argumento.

\section{REAJUSTE DE 42,95\% DA ANS: PODERIA TER SIDO MENOR?}

Em síntese, a partir dos comentários já apresentados nas seções 2 e 3 deste artigo, pode-se inferir que, no período analisado, a ANS desconsiderou a taxa de inflação do setor saúde, decisão que não favoreceu a adoção de reajustes menores entre 2001 e 2005. A afirmação desta hipótese ganha força se compreendermos ademais que:

i) a taxa de inflação do setor saúde é uma medida (proxy) dos custos das operadoras de planos de saúde

Como os bens e serviços da saúde demandados pelos consumidores se parecem com a 'cesta de consumo' das operadoras, a variação dos preços do setor saúde registrado pelo índice de preço ao consumidor acabariam retratando, de forma aproximada, os custos médios dos planos. Se tal aferição não particulariza os extremos da distribuição dos gastos (variabilidade de preços e quantidades) com hotelaria, material médico-hospitalar e medicamentos, essa característica técnico-científica intrínseca à construção dos índices ao consumidor não impede que os planos com melhores coberturas estejam cada vez mais dispendiosos para os consumidores. Em outras palavras, as operadoras, na prática, já contornam a aparente limitação do índice e apreçam os planos cujos sinistros esperados se encontram na cauda superior da distribuição dos gastos;

ii) a taxa de inflação do setor saúde foi menor do que a inflação da economia

No contexto da abertura da economia brasileira, a peça-chave para entender a estabilidade dos preços do setor saúde, mas não exatamente a dos planos, reside no comportamento da taxa de câmbio, da política governamental na área de medicamentos e do próprio Sistema Único de Saúde (SUS). Supõe-se que a inflação setorial foi menor do que a inflação da economia devido à combinação de três fatores, contrariando as expectativas teóricas acerca dos custos crescentes nesse período: a) a minimização da pressão dos custos dos insumos importados, no contexto da sobrevalorização do câmbio (p.ex. órteses, próteses, insumos laboratoriais e medicamentos etc.); b) a política governamental na área de medicamentos mediante o controle dos reajustes dos preços dos remédios de uso continuado, o programa da farmácia popular, os genéricos e a isenção fiscal de algumas substân- 
cias; c) apesar do estrangulamento estrutural da oferta, o SUS preenche, em parte, as necessidades de saúde da população, reduzindo o peso do setor saúde no orçamento das famílias e a participação dos seus bens e serviços na formação dos índices de preço ao consumidor, que, do ponto de vista de Braz, são muito expressivos (Braz, 2006);

iii) a evolução dos preços dos planos coletivos está descolada da taxa de inflação do setor saúde

Em muitos casos, os planos coletivos abrangem tão-somente uma 'soma de indivíduos' não organizados e sem poder de barganha sobre os preços nos contratos realizados entre sua patrocinadora (empregador) e as operadoras. Agrega-se a isso que o processo de formação de preços se guia, em parte, pela evolução dos custos do tratamento médico, mas também pelo padrão de competição e pelo perfil de risco dos segurados.

Nessa linha, segundo Costa (1999), o cálculo atuarial aplicado aos planos de saúde é mais simples do que o aplicado nas áreas de previdência e seguros, pois trata de eventos dinâmicos, que acontecem com maior freqüência e com grandes diferenças na probabilidade de incidência, a depender do procedimento (consultas, exames, internações etc.).

O apreçamento dos planos de saúde se daria, então, a partir das seguintes variáveis: taxa de juros esperada no futuro; ramo da atividade ocupacional, idade média e distribuição do sexo da massa segurada (pooling risk); probabilidade de uso dos serviços médico-hospitalares calculada estatisticamente em razão de experiência passada ou da esperada utilização dos segurados. O peso desses fatores na composição do 'prêmio estatístico' pode ser flexibilizado, de acordo com o porte patrimonial e financeiro das operadoras, a escala do número de segurados e a estratégia de competição vis-à-vis à taxa de rentabilidade ótima. No entanto, para fazer face ao pagamento dos sinistros futuros, deve-se estimar o preço acima do 'prêmio estatístico': o chamado 'prêmio puro' adiciona ao 'prêmio estatístico' um carregamento de segurança destinado a cobrir flutuações aleatórias.

Finalmente, o 'prêmio comercial' é a mensalidade que será cobrada ao segurado, formalizada, em termos muito simples, na seguinte equação: Prêmio comercial $=$ Prêmio Puro $/ 1-\beta$; onde $\beta$ (beta) $=[0,1[$ e representa um segundo carregamento administrativo de segurança para cobrir as despesas administrativas (inclusive reservas matemáticas e econômicas), a inflação dos preços médicos, hospitalares e laboratoriais, além das comissões dos corretores e o lucro esperado (Conde, 1999).

Como os planos coletivos funcionam como referência média para a adoção dos reajustes dos planos individuais uma vez que os sindicatos e os empregados não têm, em geral, poder de barganha para negociar menores preços e que o pro- 
cesso de formação de preços atende também a uma lógica atuarial, a evolução dos preços dos planos coletivos se descola da taxa de inflação do setor saúde mensurada pelos índices oficiais de preço ao consumidor — que é uma medida (proxy) dos custos das operadoras de planos de saúde, comprotendo o realismo da política de regulamentação de preço da ANS;

\section{iv) a adoção de índices próprios para fins de reajuste dos preços dos planos individuais antigos é problemática}

Primeiro, a aplicação da VCMH como base para sancionar um índice próprio fere, na essência, a idéia de se aplicar uma regulação por desempenho. Esse tipo de regulação é hoje praticada pela agência reguladora em relação aos preços dos planos individuais novos, que procura eliminar os excessos de assimetria de informação, para evitar que as ineficiências difusas das operadoras sejam repassadas aos consumidores.

Segundo, existe o perigo de se fomentar a indexação da economia, que colocaria em risco o próprio regime de metas do BACEN. De tal modo que, caso se difunda a aplicação de índices próprios, tal processo poderá contaminar a economia, em um cenário macroeconômico já marcado pela desindexação (Reis, 2004). Vale lembrar, no contexto do Programa de Incentivo à Adaptação de Contratos (PIAC), a ANS recusou as propostas de índice próprio, pois foram apresentadas pelas operadoras com graves inconsistências.

Se não foi possível demonstrar até agora a nossa hipótese, a qual advoga que o reajuste de $42,95 \%$ da ANS foi excessivo, conseguimos esclarecer à primeira vista, qual teria sido a relevância de se cotejar — no período analisado - a taxa de inflação do setor saúde, funcionando como um preço-teto (price-cap) de referência na definição do teto de reajuste dos planos individuais de saúde. Por se tratar de índice oficial de preço, este fato poderia também ter revertido a posição de fragilidade da ANS após a decisão do STF no caso da remarcação dos preços dos planos individuais antigos, em especial se a autoridade regulatória tivesse feito valer a presença dos incentivos governamentais (renúncia arrecadação fiscal), que patrocinam o consumo de planos de saúde por meio da renúncia de arrecadação fiscal, para refrear tecnicamente o valor do teto dos reajustes.

\section{CONSIDERAÇÕES FINAIS}

Com o surgimento da ANS em 2000, a dinâmica dos preços não pode ser mais vista fora de uma dimensão institucional, distante do campo das políticas públicas. Se não bastasse a presença do SUS, cujo nível de cobertura e o volume de compras afetam o sistema de preços, estamos diante de um quadro complexo no tocante às regras dos reajustes dos planos de saúde definidas pela ANS.

Neste artigo vê-se que a taxa de inflação do setor saúde foi estável e inferior à 
inflação da economia - resultado que legitimaria a aplicação de um reajuste da ANS menor do que $42,95 \%$, com base nos índices oficiais de preço. Contudo, esta discussão não se esgotou, considerando que tanto os índices oficiais de inflação da saúde quanto a metodologia de apreçamento dos planos individuais merecem ser amplamente debatidos.

A ANS é o órgão governamental a ser ouvido no âmbito do Sistema Nacional de Defesa do Consumidor a respeito de práticas abusivas na adoção de cláusulas de impacto financeiro e nas situações de risco à saúde. Para que a regulamentação dos preços dos planos de saúde ajude a promover a defesa do consumidor e a concorrência regulada, formulamos duas propostas de política, que poderão ser examinadas em estudos posteriores.

A taxa de inflação do setor saúde como um índice exclusivo para parametrizar as ações regulatórias da ANS parece insuficiente. Por isso, de um lado, poder-se-ia construir um índice específico voltado para os hospitais, semelhante ao Índice de Preço ao Produtor (Producer Price Index - PPI), implantado nos Estados Unidos em dezembro de 1991, para avaliar esse custo específico das operadoras de planos de saúde. De outro, radicalizando o modelo da regulação por desempenho e sem o ônus da burocratização com a edição sistemática de normas, portarias e resoluções normativas da ANS, poder-se-ia identificar empresas-modelo (benchmarks), visando fundamentar a política de reajuste dos planos individuais e coletivos, a partir do próprio mercado.

De qualquer modo, é necessário ampliar as investigações acerca da dinâmica inflacionária da área da saúde, bem como explorar a tese dos custos crescentes, no bojo do processo de concentração e de consolidação do capital financeiro no mercado de planos de saúde brasileiro. Outra temática a ser examinada é a da escalada dos custos em nível internacional, para discutir se tal aumento produziu melhores condições de saúde da população e uma atenção médica com mais qualidade, ou, se apenas promoveu preços maiores como foi o caso dos Estados Unidos. Finalmente, permanece aberta a polêmica em torno do grau de intervenção do Estado no mercado de planos de saúde.

\section{REFERÊNCIAS BIBLIOGRÁFICAS}

Agência Nacional de Saúde Suplementar - ANS (2000) Consultas. Lei nº 9.961, de 28/janeiro/2000. Disponível em: www.ans.gov.br/portal/site/legislacao/legislacao_integra.asp?id_original=8

Agência Nacional de Saúde Suplementar - ANS (2006) Caderno de informação da saúde suplementar: beneficiários, operadoras e planos. Março. Rio de Janeiro: ANS; 2006.

BAHIA, L., e R. R. LUIZ (2006) “Informações sobre coberturas e preços de planos e seguros privados de saúde: as perspectivas de complementaridade entre fontes administrativas e de base populacional”, Revista Ciência e Saúde Coletiva, 11(4): 878-80

Banco Central do Brasil - BACEN (2004) IPCA, IPC-FIPE e IPC-Br. Diferenças metodológicas e 
empíricas. Relatório de inflação - junho/2004. Disponível em: www.bcb.gov.br/htms/relinf/ port/2004/06/ri200406b2p.pdf.

BAUMOL, W. J. (1993) "Health care, education, and cost disease: a looming crisis for public choice" Choice 77(1):17-28.

BERNDT. E. R., D. M. CUTLER, R. G. FRANK, Z. GRILICHES, J. P. NEWHOUSE e J.E.TRIPLETT (2005) "Medical care prices and output", in CULYER e NEWHOUSE, editors. Handbook of health economics. V. 1A. 4a impressão. Amsterdam: Elsevier: 119-80.

BRAZ, A.(2006) “A saúde no orçamento familiar”, Revista Conjuntura Econômica, 60(4): 50.

CARMO, H. C. E. (2004) “A teoria dos índices de preços e o sistema de metas de inflação no Brasil”. Seminário no 23 FEA-USP; Disponível em: www.econ.fea.usp.br/seminarios/artigos2/ipeset04.pdf.

CONDE, N. C. (1999) "O cálculo atuarial aplicado aos planos de saúde" (mimeo.)

COSTA, T. A. D. (1999) "O cálculo atuarial aplicado aos planos de saúde. Aplicação aos dados da Cassi”, Brasília. (mimeo.)

CUTLER, D. M. e R. J. ZECKHAUSER (2000) “The anatomy of health insurance", in CULYER e NEWHOUSE, editors, Handbook of health economics. V. 1A. $4^{a}$ impressão. Amsterdam: Elsevier. p.563-643.

Departamento Intersindical de Estatística e Estudos Socioeconômicos - DIEESE (1997). Metodologia de cálculo do ICV-Dieese. São Paulo: Boletim Dieese n ${ }^{\circ} 199$.

Instituto Brasileiro de Geografia e Estatística — IBGE (2004) Nota técnica plano de saúde 01/2004 Disponível em: www.ibge.gov.br/home/estatistica/indicadores/precos/inpc_ipca/notatecnica012004.shtm.

MEDICI, A. C.(1992) "Os serviços de assistência médica das empresas: evolução e tendências recentes”, São Paulo: Instituto de Economia do Setor Público; Texto para discussão ${ }^{\circ} 7$.

NEWHOUSE, J. P. (2001) “Medical care price indices: problems and opportunities”, National Bureau of Economic Research Working Paper, $\mathrm{n}^{\circ} 8.168$.

. (2002) Pricing the priceless: a health care conundrum. Mass: Massachusetts Institute of Technology Press.

OCKÉ-REIS, C.O., S. S. CARDOSO (2006). "Uma descrição do comportamento dos preços dos planos de assistência à saúde - 2001-2005”, IPEA Texto para discussão n 1232.

OCKÉ-REIS, C. O., F. G. SILVEIRA e M. F. S. de ANDREAZZI (2006) "O mercado de planos de saúde no Brasil: uma criação do Estado?” Revista Economia Contemporânea 10(1):157-185.

OCKÉ-REIS, C. O. (2002) “Os planos de saúde no Brasil: um estudo sobre o mercado, os gastos e a regulação”. Tese. Rio de Janeiro (RJ): Instituto de Medicina Social.

(2005).”A reforma institucional do mercado de planos de saúde: uma proposta para criação de benchmarks", in PIOLA, S.F. e E.A. JORGE, orgs., Prêmio em economia da saúde: $1^{\circ}$ Prêmio Nacional - 2004: Coletânea premiada. Brasília: Ipea-DFID: 289-324.

. (2007) “Os desafios da ANS frente à concentração dos planos de saúde”, Revista Ciência e Saúde Coletiva, 12(4): 1041-50.

PERILLO, E. B. F. (2008) “Importação e implantação do complexo médico-hospitalar no Brasil. um esboço de história econômica do sistema de saúde 1942-1945”. Tese São Paulo (SP): Universidade de São Paulo.

PHELPS, C. (1997) Health Economics. USA: Addison-Wesley

PIOLA, S. F. e S. M. VIANNA, orgs. (1995) Economia da saúde: conceitos e contribuição para a gestão da saúde. Brasília: IPEA. 
POSSAS, M. L., J. L. PONDE e J. FAGUNDES (1997) "Regulação da concorrência nos setores de infra-estrutura no Brasil: elementos para um quadro conceitual”. Brasília: IPEA-BNDES (mimeo)

REIS, E. J. (2004) “A economia brasileira no século XX”, in REIS E.P., ZILBERMAN R., orgs. Retratos do Brasil. Porto Alegre: Edipucrs: 15-38 (Coleção Memória das Letras 20.)

RIZZIERI, J. A. B. e H. C. E. CARMO (1995) Retrospectiva histórica e metodológica do IPC-FIPE. São Paulo: Fundação Instituto de Pesquisas Econômicas.

SINGER, P. (1980) Guia da inflação para o povo. Petropólis: Vozes 